\title{
LA PRENSA OFICIAL DURANTE EL SEGUNDO IMPERIO MEXICANO. EL DIARIO DEL IMPERIO (1865-1867). ${ }^{1}$
}

\author{
THE OFFICIAL PRESS DURING THE SECOND MEXICAN EMPIRE. THE DIARY OF \\ THE EMPIRE (1865-1867).
}

\author{
Óscar Ibarra Espinoza ${ }^{2}$ \\ Universidad Nacional Autónoma de México \\ DOI: 10.17533/udea.tempus.n7a03
}

\begin{abstract}
"El publicista convertido en historiador y el historiador que asume el papel de publicista conviven en perfecta y necesaria armonía en esos siglos en que se forjan los Estados nacionales de la llamada "Edad Contemporánea..."3

La hoja impresa y el diario demostraron ser el mejor medio para aquellos que deseaban moldear la opinión pública o tenían un mensaje político, literario o histórico que comunicar. ${ }^{4}$
\end{abstract}

\section{Resumen}

Este artículo es el resultado del trabajo de investigación del Seminario Multidisciplinario de Estudios sobre la prensa, de la facultad de Estudios Superiores Acatlán de la Universidad Nacional Autónoma de México; y tiene como objetivo proporcionar un panorama sobre la importancia de la prensa en la construcción política mexicana durante el siglo XIX, resaltando la utilización de ésta durante el Segundo Imperio Mexicano.

El análisis de El Diario del Imperio pretende aportar información que permita comprender, con mayor integridad, la estructura política implantada en México, como resultado de la

\footnotetext{
${ }^{1}$ Artículo recibido el 02 de octubre de 2017; aprobado el 12 de marzo de 2018

${ }^{2}$ Licenciado en Historia por la Facultad de Estudios Superiores Acatlán, UNAM, con preespecialidad en Historia Política del siglo XIX. Fue Profesor adjunto de la materia de Historia de México del Siglo XIX y formó parte del Seminario Multidisciplinario de Estudios sobre la prensa de la misma facultad. Ha participado en distintos coloquios y es autor de artículos sobre Historia Mexicana.

${ }^{3}$ Andrés Lira, "La prensa periódica y la historiografía mexicana del siglo XIX" en Aurora Cano Andaluz, Las publicaciones periódicas y la Historia de México (México, UNAM, 1995), 3.

${ }^{4}$ Stanley Robert Ross, "El Historiador y el periodismo mexicano" en Historia Mexicana, México, Colegio de México.http://codex.colmex.mx:8991/exlibris/aleph/a18 1/apache media/C15DIYLNEHX97YIG5HE2RHX SP8LJTQ.pdf 348.
} 
invasión francesa y la colocación en el trono mexicano de un príncipe de la casa de Habsburgo, además de ofrecer un acercamiento a la utilización de la opinión pública, mediante el diario imperial, para los fines requeridos por el gobierno de Maximiliano.

\title{
Palabras clave
}

Segundo Imperio Mexicano, Diario del Imperio, Maximiliano, prensa, siglo XIX, periódicos, México.

\begin{abstract}
The present article is the result of the research work of the Multidisciplinary Seminar on Press Studies, Facultad de Estudios Superiores Acatlán, Universidad Nacional Autónoma de México and aims to provide a general view of the important role of the press in the politics of XIX century, specially during the Second Mexican Empire.

The analysis of the journal El Diario del Imperio allows to understand the mexican politic structure after de French Intervention and the imposition of a prince of the House of Habsburg on the mexican throne. Likewise, is a resource to know the public opinion of the time.
\end{abstract}

\section{Keywords}

Second Mexican Empire, Diario del Imperio, Maximiliano, Press, XIX century, journals, Mexico.

\section{Introducción}

El Imperio de Maximiliano es un tema que ha sido trabajado desde muchas vertientes, la política interna, su relación con Francia, el proyecto imperial de nación, sus debilidades, sus figuras principales, la oposición de los Estados Unidos, etc., pero pocos trabajos se han abocado a reconocer el papel que desempeñó la prensa, especialmente el periódico oficial del imperio, en el juego de legitimación y consolidación al que debió enfrentarse el Segundo Imperio Mexicano. 
Cuando Maximiliano de Habsburgo y Lorena, archiduque de Austria y segundo en la línea de sucesión al trono del Imperio Austro-húngaro aceptó firmar el Pacto de Familia con su hermano y emperador Francisco José, como condición sine qua non para trasladarse a México y revivir el Imperio Mexicano, jamás se imaginó, o no quiso ver, que en su nueva patria contaría con tan pocos aliados y sí con una gran cantidad de adversarios, tanto al interior como al exterior.

Por ello, tuvo que idear una manera de cambiar tan complicada situación y tratar por todos los medios a su alcance revertir la percepción, en el peor de los casos negativa, en el mejor de ellos indiferente, de sus súbditos y las potencias extranjeras con las que obligadamente debía entablar relaciones diplomáticas para afianzar su gobierno.

Uno de los mecanismos que utilizó para lograr dicho objetivo fue la prensa, para transmitir una imagen de orden, progreso y modernidad alcanzada por los actos llevados a cabo desde los ministerios que conformaban la estructura imperial.

Desde los primeros años de la guerra civil protagonizada por los liberales y conservadores mexicanos, la prensa se manifestó como uno de los medios más útiles y socorridos para sostener y apoyar el proyecto político propio, o demeritar el del adversario, lo mismo que para dar a conocer ideas, planes y disposiciones de las autoridades del país, por ello a la llegada de Maximiliano, ya existía una añeja tradición periodística literaria que conformaba una nutrida red de organismos de opinión pública, constantemente utilizada en el convulso siglo XIX mexicano.

Esta época es rica en opiniones, principalmente políticas, las cuales vertidas en la prensa, contribuyeron al enriquecimiento de la discusión inherente a la construcción de México como nación soberana y a la formación de una clase política muy ligada a los periódicos, mediante los cuales promovieron variadas perspectivas gubernativas, pasando por la república federal y central, la dictadura y, en este caso, el imperio.

\footnotetext{
${ }^{5}$ El 8 de abril de 1867 en el Castillo de Miramar Maximiliano decidió aceptar las condiciones estipuladas por Francisco José, para darle la autorización, como cabeza de la familia Habsburgo, para aceptar la corona mexicana que con anterioridad una comisión de eminentes conservadores mexicanos le ofreció, a dichas condiciones se les conoce como Pacto de Familia, entre las cuales destaca, la renuncia de Maximiliano y sus descendientes a sus títulos y derechos sucesorios al trono austriaco.
} 
El binomio política-prensa, en el México decimonónico, se impuso como uno de los factores esenciales en el desarrollo del Estado-Nación. Fue en el escenario de la discusión periodística donde se manifestaron los distintos programas de gobierno que surgieron, como resultado de la separación mexicana del poder español; con el objeto de lograr la construcción de un proyecto de nación independiente del que había privado por trescientos años. Esto permitió a la prensa revelarse como una útil herramienta de justificación, de ahí que las publicaciones periódicas fueran un elemento muy destacado en la lucha por el poder y el manejo de la opinión pública.

Los periódicos como fuentes para el estudio del siglo XIX mexicano, especialmente del periodo que comprenden la Reforma, la Intervención Francesa y el Segundo Imperio, son muy importantes si tomamos en cuenta que a pesar de que el periódico no es una fuente irrecusable, sí puede proveernos de un relato continuo de los sucesos contemporáneos de una localidad.

La prensa mexicana ofrece al historiador un sinnúmero de artículos y memorias históricas, documentos, relatos, análisis y polémicas ${ }^{6}$ que fueron parte fundamental de los procesos históricos y de opinión pública, encargándose de generar y encausar opiniones sobre el rumbo político que cada uno de los grupos, que se disputaban el poder, tenía contemplado para la nación; ya fuertemente definidos desde la Guerra de Reforma hasta el Imperio de Maximiliano.

La opinión pública durante la época decimonónica estuvo reducida, a los pocos que se interesaban de manera constante sobre los acontecimientos económicos, políticos y sociales del momento; de ahí que los conflictos ideológicos no llegaron a la mayoría de los niveles sociales, pues la población que de ellos se enteró fue en su mayoría citadina letrada, los analfabetas se enteraron de los acontecimientos por medio de la palabra, aunque eso no significó que tomaran parte de la disputa en el escenario periodístico, como sí lo hacían la élite social mexicana ${ }^{7}$, pues la opinión pública se circunscribía al grupo que disponía de

\footnotetext{
${ }^{6}$ Stanley Robert Ross, "El Historiador y el periodismo mexicano", 347.

${ }^{7}$ Adriana Pineda Soto y Celia del Palacio Montiel (coord.), La prensa decimonónica en México: objeto y sujeto de la Historia (México, Universidad Michoacana de San Nicolás de Hidalgo/Universidad de Guadalajara/CONACYT, 2003), 231. Véase también Laura Navarrete Maya y Blanca Aguilar Plata (coord.), La prensa en México. Momentos y figuras relevantes (1810-1915) (México, Pearson, 1998), 68.
} 
medios pecuniarios para hacerse de los periódicos, los militantes de las facciones y los que adquirían un alto nivel educativo y económico interesados por la información.

También es importante decir que los editores y redactores de la época tenían una fuerte implicación política, pues tanto liberales como conservadores eran abogados, literatos, religiosos, militares y académicos; profesiones que sirvieron de escaño para la crítica al oponente, las cuales les permitieron alcanzar altos puestos públicos y hacer uso de las publicaciones periódicas con la finalidad de imponer su proyecto de gobierno. ${ }^{8}$

La lucha en el contexto literario nos permite conocer y analizar ideales políticos, propuestas gubernamentales y legislativas, además la manera en que las presentaban al público, observar similitudes y diferencias entre las distintas propuestas y de esta manera conocer en perspectiva el desarrollo del proceso de consolidación de la política mexicana en el siglo XIX, en otras palabras "la prensa periódica jugó un papel importante en la transformación de la nación, pues se convirtió en la plataforma que las facciones utilizaron para defender su posición y criticar la del enemigo, por lo que asumió un tono abiertamente político", de ahí que el periódico adquiriera dos funciones la meramente informativa y la otra doctrinal, pues a la par de que se informaba se difundía la ideología de tal o cual tendencia política. $^{9}$

La información y la opinión permitieron crear escenarios ideológicos propicios para argumentar posturas políticas y convencer a los lectores de la necesidad de aplicar una fórmula particular que llevara al país a la consolidación de sus instituciones y de su vida independiente; por ello la prensa mexicana del siglo XIX se manifestó como un periodismo político-social, el cual durante la Reforma, la Intervención Francesa y el Imperio contribuiría a cimentar la ideología de un sistema de gobierno que asegurara el crecimiento, la estabilidad y el fortalecimiento de un país que durante el trayecto de su vida independiente no había tenido reposo por los constantes enfrentamientos políticos internos y externos, el estancamiento económico y el atraso político, social y cultural en que la inestabilidad lo postraba. $^{10}$

\footnotetext{
${ }^{8}$ Adriana Pineda Soto y Celia del Palacio Montiel, La prensa decimonónica en México, 230.

${ }^{9}$ Laura Navarrete Maya y Blanca Aguilar Plata, La prensa en México, 67.

${ }^{10}$ Laura Navarrete Maya y Blanca Aguilar Plata, La prensa en México, 68.
} 
La prensa destacó como tribuna política en las controversias del momento, haciendo del conocimiento público las propuestas y acciones en la batalla por el poder, por ello contiene información que permite conocer y comprender la lucha entre liberales y conservadores que desencadenaría la instalación del Segundo Imperio, ya que;

habiéndose aumentado el caudal de publicaciones críticas sobre los sucesivos presentes del país, las actualidades políticas se acumularon en las páginas de la prensa, y si bien ésta siguió siendo más que nada un órgano expresivo de opiniones, éstas eran también testimonio de momentos concretos que, pasados por el tamiz de la crítica, se fueron convirtiendo en fuente o material para la historiografía, y llegaron a constituir la fuente primordial, puesto que el asunto principal, precisamente la política, se había ido conformando en buena medida en la prensa. ${ }^{11}$

\section{Antecedentes}

Antecedieron al periodo de gobierno de Maximiliano en México, diversas publicaciones que formaron parte activa de la disputa por el poder en el escenario nacional y local entre los liberales y los conservadores, sentando las bases de una sociedad bastante familiarizada con las publicaciones periódicas, como parte importante de la vida pública, permitiendo que a la llegada del emperador austriaco, éste viera en los periódicos un aspecto esencial de su política y su relación con el público.

Como defensores de la causa liberal republicana podemos mencionar a $E l$ Republicano de Puebla (1855-1856) encargado de publicar la ideología liberal en una región de mayoría conservadora, tal vez por esta circunstancia es importante su labor periodística en favor de la causa liberal, fue redactado por Pantaleón Tovar ${ }^{12}$ y editado por Ignacio

\footnotetext{
${ }^{11}$ Andrés Lira, "La prensa periódica y la historiografía mexicana”,8.

12 Pantaleón Tovar y Morquecho (1828-1876) Periodista, historiador, poeta y novelista, fue liberal radical, ocupó una diputación tras la guerra de Reforma y en 1861, junto con otros legisladores la renuncia del presidente Juárez. Fue redactor del periódico El siglo Diez y Nueve. Efemérides del periodismo Mexicano. Cambio Digital, agosto 2011. http://cambiodigital.com.mx/mosno.php?nota=71371.
} 
Cumplido, ${ }^{13}$ también existieron Pata de Cabra (1855) dirigido por Juan de Dios Arias, ${ }^{14}$ La

Chinaca (1862-1863) periódico opositor a la Intervención Francesa, redactado por Alfredo Chavero, ${ }^{15}$ Pedro Santacilia ${ }^{16}$ y Guillermo Prieto ${ }^{17}$ entre otros, La Orquesta (1861-1867), periódico satírico liberal, dedicado en gran medida a la caricatura, dirigido por Hilario Soto y Frías, ${ }^{18}$ y La Sombra (1865-1866) el cual fue suprimido por atacar al Imperio.

Como antecesor del Diario del Imperio, ya que fue también un periódico oficial, encontramos el Diario del Gobierno de la República Mexicana (1863) publicado en San Luis Potosí durante la retirada de Benito Juárez ante el avance del ejército francés.

Así como los periódicos anteriores nos dan un perfil de las preocupaciones ideológicas y políticas liberales, los siguientes nos muestran las posturas conservadoras hacia temas como la relación liberal con Estados Unidos y la necesidad de una monarquía mexicana, encabezada por un príncipe europeo, las cuales fueron tema constante en la prensa y motivaron diversos artículos, en diarios como La Espada de Don Simplicio (1855-1856) periódico de sátira contrario a la Reforma Liberal, La Cruz (1855-1858) revista que defendió

\footnotetext{
${ }^{13}$ Ignacio Cumplido nació en Nueva Galicia (Guadalajara) en 1811, es considerado el editor más prolífico del siglo XIX mexicano, estuvo siempre ligado a las ideas liberales, entre los periódicos que editó están El correo de la Federación, El Fénix de la Libertad, El Atleta y el más destacado fue El Siglo Diez y Nueve, fue introductor de importantes reformas a la tipografía mexicana, para saber más veáse Vicente Quirarte, Ignacio cumplido, artista y empresario del siglo XIX, (México, Instituto de Investigaciones Dr. José María Luis Mora, 2001).
}

${ }^{14}$ Juan de Dios Arias fue escritor, periodista y satírico, entre sus obras destaca Reseña de las campañas del Ejército del Norte, publicó los periódicos la Sombra y la Orquesta y participó en la creación del texto México a través de los siglos, para saber más véase Ruedas de la Serna, Jorge, La Misión del escritor. Ensayos mexicanos del siglo XIX, (México, Universidad Nacional Autónoma de México, 1996), 295-303.

15 Alfredo Chavero (1841-1906) Nació en la Ciudad de México, abogado de profesión, también fue poeta, dramaturgo, historiador, arqueólogo y político de tendencia liberal, fue Regidor del Ayuntamiento de la Ciudad de México, diputado y director del Museo Nacional, participó en la creación del texto México a través de los siglos, http://www.centenarios.org.mx/Chavero.htm

${ }^{16}$ Pedro Santacilia (1826-1910) nació en Santiago de Cuba, fue poeta, maestro y colaborador en varias publicaciones periódicas, tanto en Cuba como en el extranjero, fue yerno de Benito Juárez con el cuál luchó por la soberanía mexicana en los distinto momentos en que Juárez fue presidente del país, http://www.cambiodigital.com.mx/mosno.php?nota=296454

${ }^{17}$ Guillermo Prieto (1818-1897) nació en la Ciudad de México, fue protegido de Andrés Quintana Roo y así pudo continuar con sus estudios, fue escritor, cuentista, novelista, poeta, cronista, ensayista y político, ocupó varios puestos de gobierno, como la secretaria de Hacienda y la una diputación en el Congreso Liberal de 1857, además fue testigo y partícipe de varios conflictos interno y externos del país durante el siglo XIX. http://www.historicas.unam.mx/publicaciones/publicadigital/libros/lecturas/T2/LHMT2_028.pdf, 310-311.

${ }^{18}$ Hilario Soto y Frías (1831-1905) médico de profesión, fue secretario del gobierno de Querétaro, participó en la guerra de Tres Años por el bando liberal, combatió a la intervención francesa y al Imperio, fue diputado durante la República Restaurada y colaboró en varios periódicos de la época, http://www.centenarios.org.mx/FriasySoto.htm 
la religión católica ante la Constitución de 1857, redactada por Clemente de Jesús Munguía, ${ }^{19}$ José María Roa Bárcena ${ }^{20}$ y José Julián Tornel y Mendivil, ${ }^{21}$ El Pájaro Verde (1861) opuesto a las Leyes de Reforma, Le Trait d'Union (1850-1892) periódico francés, el cual después de su tradición republicana se inclinó por la defensa de la monarquía. ${ }^{22}$

Como podemos observar existió una diversidad de publicaciones periódicas, que nos dan referencias de la importancia de este medio de comunicación para la política del periodo, en consecuencia es lícito aceptar que, durante estos años "la política [fue] impensable sin prensa, ya que el poder la necesita, trata de cooptarla, de evitar que se le oponga, de que convalide sus actos, el poder público necesita de una prensa oficial, de otra oficiosa y de la independiente, pero también la prensa cumple con una función social, le da a los consumidores una información requerida". ${ }^{23}$

En los casos anteriores la prensa desempeña una función esencial en la vida pública y es testigo de los procesos históricos de su época. Echando mano de la información que las publicaciones nos ofrecen, se abona considerablemente a la explicación y comprensión de un periodo tan relevante para la definición política de México. ${ }^{24}$

A pesar de las múltiples restricciones que la libertad de imprenta sufrió en distintos momentos en México, la proliferación de periódicos favorables o detractores del gobierno en

\footnotetext{
${ }^{19}$ Clemente de Jesús Munguía (1810-1868) nació en Michoacán, fue sucesor de Cayetano Gómez de Portugal en el obispado de Puebla y fue nombrado por Pio IX delegado y visitador apostólico, fue expulsado durante el Imperio de Maximiliano y murió en Roma, http://www.memoriapoliticademexico.org/Biografias/MCJ10.html ${ }^{20}$ José María Roa Bárcena (1827-1908) nació en Jalapa, fue historiador, novelista, crítico, periodista y poeta, entre sus obras más destacadas se encuentra Recuerdos sobre la invasión norteamericana por un joven de entonces, http://www.centenarios.org.mx/Roa.html

${ }^{21}$ José Julián Tornel y Mendivil (1801-1860) nació en Orizaba, fue hermano del general José María Tornel y Mendivil quién lo impulsó en sus estudios y en los puestos políticos, estudió en el colegio de San Idelfonso y se recibió como doctor en filosofía, teología y derecho civil y canónico, fue receptor del pensamiento francés y continuador de la tradición lógica mexicana. María del Carmen Rovira [coord.], Pensamiento filosófico Mexicano del sigo XIX y primeros del XX (México, Universidad Nacional Autónoma de México, 2001 ); 43.

${ }^{22} \mathrm{La}$ información de los periódicos antes mencionados fue extraída de María del Carmen Ruiz Castañeda (coord.), La prensa. Pasado y presente de México (México, Universidad Nacional Autónoma de México, 2da Edición, 1990), 71-100. Para conocer otros periódicos publicados en éste u otros periodos de la Historia de México consúltese a Miguel Velasco Valdés, Historia del periodismo mexicano (apuntes), (México, Manuel Porrúa, 1955).

${ }^{23}$ Álvaro Matute, "Prensa, sociedad y política (1911-1916) en Aurora Cano Andaluz. Las publicaciones periódicas y la Historia de México (México, Universidad Nacional Autónoma de México, 1995), 63-64.

${ }^{24}$ Para conocer más sobre las publicaciones que se emitieron, tanto por liberales como por conservadores, durante estos años véase Angélica Hernández. "La libertad de Imprenta en la Ciudad de México durante el segundo Imperio" en Historias. Revista de Estudios Históricos del Instituto nacional de Antropología e Historia, (México, INAH, no. 42, enero-abril 1999).
} 
turno, nos da una muestra del destacado papel que intelectuales, políticos y autoridades mexicanas dieron a la prensa y los esfuerzos por asegurar una libertad de imprenta, que aún en ciernes, ya daba visos de convertirse en parte esencial de la vida nacional.

Resaltan dos ejemplos que nos explican la proliferación de periódicos implicados en los sucesos políticos y armados, uno es la ley de Libertad de Prensa de José María Lafragua 25 y la estipulada en el Estatuto Provisional del Imperio de $1865,{ }^{26}$ dichas disposiciones permitieron que la lucha en los campos de batalla, estuviera estrechamente acompañada de la disputa literaria; las armas también fueron las plumas que acompañaron en buena medida a las acciones militares.

La prensa oficial hizo aparición como elemento de sustancial importancia para la consolidación de un régimen político, estos periódicos fungirán como voceros de la administración en turno, liberal, conservadora o monarquista, pues fueron la voz autorizada por el gobierno para informar sobre sus actos, leyes y decretos, por lo que asumió un carácter principalmente informativo, sin dejar de lado la defensa del régimen. ${ }^{27}$

\section{La prensa oficial durante la Intervención y el Imperio}

Durante la Intervención Francesa apareció un periódico, que intentaba legitimar el proceso de instalación de Maximiliano en el trono mexicano, denominado Periódico Oficial del Imperio, fue un órgano bilingüe elaborado por la Regencia, integrada por Juan N. Almonte, Mariano Salas y Juan B. Ormaechea en representación del obispo de México Pelagio Antonio de Labastida y Dávalos, publicado por primera vez el $1^{\circ}$ de octubre de 1863 , el cual se convertirá después en El Diario del Imperio. ${ }^{28}$

\footnotetext{
${ }^{25}$ Ley de pre-reforma promulgada el 28 de diciembre de 1855 por José María Lafragua, la cual manifiesta que "ninguna persona podrá ser molestada por sus opiniones, ya que todo ciudadano tiene derecho a imprimirlas y circularlas sin censura ni pago de fianza". Laurence Coudart, "La regulación de la libertad de prensa (18631867)", en Historia Mexicana 65, $\mathrm{n}^{\circ} 2$ (2015), 629.

${ }^{26}$ El Estatuto provisional del Imperio estipulaba en su artículo 76 que "a nadie puede molestarse por sus opiniones ni impedírsele que las manifieste por la prensa, sujetándose a las leyes que reglamentan el ejercicio de este derecho". Maximiliano de Habsburgo, Estatuto Provisional del Imperio (México, 10 de abril de 1865, imprenta de Andrade y Escalante, Bajos de San Agustín, número 1), 12, http://www.ordenjuridico.gob.mx/Constitucion/1865.pdf

${ }^{27}$ Laura Navarrete Maya y Blanca Aguilar Plata, La prensa en México, 72 y 73.

${ }^{28}$ Miguel Velasco Valdés, Historia del periodismo mexicano, 94.
} 
Ya instalada la pareja imperial en México, Maximiliano buscará popularizar su régimen dentro del país, como en el extranjero, para ello utilizará la prensa de manera importante. Su gobierno subvencionaba, aparte de El Diario del Imperio, dos periódicos más, el Ere Nouvelle y La Razón, estas publicaciones tenían como misión resaltar las bondades del orden implantado y gozaban de grandes dotaciones económicas. ${ }^{29}$

Un aspecto decisivo durante el periodo imperial de Maximiliano en México, fue la atención a la opinión pública internacional, al estar íntimamente relacionado el imperio con intereses económicos y expansionistas de dos grandes potencias de la época, Francia a favor y Estados Unidos en contra, surgió la imperiosa necesidad de atender y orientar, en su favor, la opinión pública tanto en Europa como en Estados Unidos.

Para ello, el archiduque, creó una oficina de prensa dirigida por el abate francés Emmanuel Domenech, "también tenía en Viena, Nueva York y Paris agentes especiales cuya labor consistía en influir en la mayor escala posible las opiniones de la prensa local sobre el Imperio, para que ésta se dedicara a publicar noticias favorables al imperio y rechazar cualquier texto peligroso para el gobierno imperial". 30

Maximiliano impuso al gabinete imperial, entre sus principales actividades, la de relacionarse con la prensa nacional y extranjera, de tal modo que le fuese posible, en caso dado, dirigir favorablemente la opinión pública por medio de artículos inspirados en la exaltación de los logros obtenidos por la administración imperial, además de mantenerse en contacto con la policía secreta y disponer de agentes confidenciales para informarse sobre el ánimo general, encargando de tal misión a la Secretaría del gabinete imperial presidida por el ministro belga Félix Eloin. ${ }^{31}$

Como ejemplo de la importancia de la prensa para el Segundo Imperio Mexicano, es importante destacar que mientras más cerca estaba el fin de la Guerra de Secesión, Maximiliano veía la caída de su imperio con mayor desesperación, sobre todo porque

\footnotetext{
${ }^{29}$ A.B. Belenki. La Intervención Extranjera de 1861-1867 en México (México, Ediciones de Cultura Popular, 1984), 158.

${ }^{30}$ A.B. Belenki. La Intervención Extranjera, 158 y 159.

${ }^{31}$ Félix Eloin era belga, ingeniero de minas y fue encomendado por Leopoldo I a su yerno Maximiliano por sus cualidades políticas y de administración pública que consideraba, le serían útiles en la organización administrativa del Imperio Mexicano, véase Egon Caesar Conte Corti, "Después de aceptar la corona" en Maximiliano y Carlota (México, Fondo de Cultura Económica, 2004), 275 y 276.
} 
aparecían en Estados Unidos, al parecer promovidas por los liberales mexicanos y algunos ciudadanos estadunidenses, organizaciones que atacaban al emperador, entre las cuales destaca en Nueva York el "Club de patriotas mexicanos".

El gobierno imperial decidió contrarrestar tal oposición utilizando la prensa como aliada, por ello el emperador envió repetidas veces agentes propios a Nueva York, por ejemplo al conde Ollivier Rességuier con la misión de influir entre los capitalistas y de ser posible comprar a la prensa, "lo que también [se] intentó, por supuesto con Gordon Bennett" el fundador del importante periódico New York Herald, para de este modo preparar el camino para un eventual acercamiento y reconocimiento por parte del gobierno en Washington. ${ }^{32}$ También el marqués de Montholon, ministro francés en Washington, recomendó en 1865, "que se destinaran mil pesos mensuales para modificar el lenguaje de la prensa americana desfavorable al Imperio." 33

Además el emperador proyectó una gabinete de prensa especial para influir en la opinión pública europea, la cual conforme avanzaba el tiempo cada vez le era más adversa por ello dispuso que el centro para la prensa de los países occidentales sería Paris, para la de los países alemanes, Viena y para contar con mejores resultados "se trabajaría bajo dos resortes, el dinero y la concesión de condecoraciones". ${ }^{34}$

\section{EI Diario del Imperio. El periódico oficial de Maximiliano}

El objetivo de un periódico publicado por el Estado es hacer propaganda de sus logros, minimizar sus problemas y deficiencias con el fin de fomentar una imagen, no siempre real, de estabilidad ${ }^{35}$, este papel lo desempeñó El Diario del Imperio, con el objetivo principal de legitimar al estado imperial encabezado por Maximiliano de Habsburgo, ante esta necesidad se creó este diario oficial ${ }^{36}$ mediante el siguiente decreto imperial:

\footnotetext{
32 "La mayoría de las veces informaban al emperador solo lo que este oía con gusto y se complacían en todo género de jactancias, así por ejemplo Estvan, le comunicaba que los principales periódicos de Norteamérica estaban bajo su "mando" y estaban subvencionados por él." Egon Caesar Conte Corti, "Después de aceptar la corona", 368.

${ }^{33}$ José Fuentes Mares, “Los Estados Desunidos de América” en Juárez: Los Estados Unidos y Europa, (México, Grijalbo, 1983), 118.

${ }^{34}$ José Fuentes Mares, "Los Estados Desunidos de América”, 415.

${ }^{35}$ Manuel Castells, Comunicación y poder (Madrid, Alianza editorial, 2009).

36“Ministerio de Estado y Negocios Extranjeros" en El Diario del Imperio, (México $1^{\circ}$ de enero de 1865, Tomo I, núm. 1), 1.
} 
Maximiliano Emperador de México.

Hemos venido en decretar y DECRETAMOS [sic] lo siguiente:

Art. $1^{\circ}$.- El Periódico Oficial del Imperio Mexicano, tendrá en lo sucesivo el título de "Diario del imperio" y se publicará por ahora todos los días de la semana, excepto los lunes.

Art. $2^{\circ}$.- Se insertarán en él todas las leyes, decretos, órdenes y circulares, y con su inserción serán obligatorios en el Imperio, sin necesidad de otra promulgación.

Art. $3^{\circ}$.- Los tribunales y jueces de la capital y de su distrito enviarán al periódico oficial, los avisos judiciales y publicados en él, producirán sus efectos legales.

Art. $4^{\circ}$.- Ningún periódico podrá publicar documento alguno oficial, que antes no haya aparecido en el Diario del Imperio.

Art. 5.- Todas las oficinas del Gobierno Imperial deberán suscribirse al periódico oficial.

Nuestro ministro de Estado y Negocios Extranjeros queda encargado de la ejecución de este decreto, que se depositará en los archivos del Imperio.

Firmado: Maximiliano

Firmado: José Fernando Ramírez (Secretario de Estado).

Es evidente la importancia que se le dio al diario imperial como vehículo para transmitir las disposiciones y decretos necesarios para la adecuada conducción de los asuntos gubernamentales; además de ser la mejor opción, para la comunicación entre gobierno y súbditos.

De su publicación se encargaron José María Andrade y Felipe Escalante, quienes adquirieron la imprenta de Rafael de Rafael en 1854, desde sus primeros momentos mantuvieron estrecha relación con el partido conservador, por lo cual los socios impresores iniciaron publicando trabajos históricos, religiosos y algunos periódicos como La Cruz; lograron la concesión imperial para editar El Diario del Imperio, ya que la instalación del gobierno imperial se debía justamente al partido conservador. 
Durante el periodo del Imperio publicaron escritos de José María Gutiérrez de Estrada, del emperador Maximiliano y de índole conservadora. La imprenta dejó de producir en el mismo año del fin del imperio. ${ }^{37}$

El diario se publicó entre el 1 de enero de 1865 y 19 de junio de 1867 y estaba dividido en distintas secciones donde se trataban los temas de importancia para la política interior y exterior, la cultura, el desarrollo del campo, los protocolos, los reglamentos, entre otros. El periódico se estructuró de la siguiente manera ${ }^{38}$ :

Parte Oficial: En ésta sección se publicaban los decretos imperiales provenientes de Maximiliano o de cualquiera de los Ministerios de Gobierno. De ésta manera se cumplieron dos objetivos, claramente establecidos en el decreto de fundación, las disposiciones se hacen del conocimiento de todos los interesados y se les da carácter legal para su ejecución.

El Parte Oficial tuvo por objeto la expedita aplicación de las disposiciones legales y jurídicas emanadas de los ministerios que conformaban el gobierno imperial, para obtener un mejor funcionamiento de la maquinaria institucional de la que el Emperador se valía para gobernar. Con dichas publicaciones se delimitaban las funciones de los distintos niveles de gobierno dentro del Imperio, además de establecerse la transparencia en las funciones de cada dependencia, con ello se buscaba regresar al país al orden que se había perdido por los largos años de enfrentamientos políticos. Los temas que se trataban en esta sección eran:

- Condecoraciones: Otorgadas por el Emperador a través de la Gran Cancillería de las Órdenes Imperiales, con ellas se distinguían a diplomáticos mexicanos o extranjeros, a los Ministros Imperiales y a los soldados distinguidos, ya sea del cuerpo expedicionario francés o del ejército mexicano. También se establecía el protocolo a seguir durante las ceremonias oficiales y el lugar que cada invitado debía ocupar, según su rango.

- Nombramientos y disposiciones: Publicación de disposiciones respecto a los dignatarios extranjeros o nacionales, concernientes a nombramientos de Ministros

\footnotetext{
37 La república de las letras: asomos a la cultura escrita del México decimonónico, (México, UNAM, Filológicas, Bibliográficas, Históricas, Vol. II, 2005), 18-19.

${ }^{38}$ Esta división fue realizada por el autor con base en la consulta directa de El Diario del Imperio.
} 
Plenipotenciarios, Cónsules, Ministros, Integrantes del Consejo de Ministros o del Consejo de Estado, autoridades civiles y militares, entre otros. También se publicaban las reglas y órdenes sobre el cumplimiento de sus funciones y los límites de su jurisdicción.

- Privilegios: Aquí se trataban temas sobre derogación o aceptación de privilegios comerciales sobre rutas de transporte, minas, tierras, importación de mercancías y tecnologías, colonización, etc. También se disponía sobre los privilegios honoríficos civiles o militares.

- Disposiciones legales: Dichas disposiciones tenían por objeto regular la situación legal de los súbditos, sobre todo respecto a sus bienes materiales, principalmente herencias, que se daban a través del Ministerio de Justicia o directamente del Emperador. También se hacía del conocimiento público las tasación de impuestos (rentas) y la obligación de cumplir con el pago puntual de los mismos, a través del Ministerio de Hacienda.

Otras disposiciones eran las que el Ministerio de Fomento emitía en los ramos de infraestructura, colonización e instrucción pública.

- Instalación de autoridades imperiales: Nombramiento de ayuntamientos o autoridades locales civiles o militares, en la capital o en las provincias. Instrucciones para el desempeño de sus funciones, ya sea de autoridades locales o de los Ministros Imperiales.

- Reglamentos: Maximiliano se dio a la tarea de publicar reglamentos para distintas ocasiones, entre otros están los que organizaban los gobiernos provinciales, la colonización (creación de la Junta de Colonización), el otorgamiento de condecoraciones y para las realización de los actos solemnes, los reglamentos para las acciones y atribuciones de las autoridades imperiales (Consejo de Ministros, Consejo de Estado, los Ministerios, el ejército, etc.), para la organización y entrenamiento militar, para la creación de un cuerpo de policía para la seguridad pública, para la división territorial del Imperio y respecto de sueldos para dichas 
autoridades; además de lineamientos y atribuciones para la creación de compañías de transporte, colonización, comercio, beneficencia, entre otros.

- Organización Imperial: En ésta sección se hacía oficial la remoción de los Ministros Imperiales y el nombramiento de los sustitutos, de autoridades provinciales civiles y militares y de Ministros Plenipotenciarios o Cónsules

- Naturalización y tránsito: A través del Ministerio de Estado y Negocios Extranjeros se hacía oficial el reconocimiento de naturalización de extranjeros que querían radicar en el Imperio como súbditos, también se publicada la procedencia, el número y el puerto de llegada de extranjeros y mexicanos.

- Legislación: Derogación y aplicación de leyes

- Actividades de los Emperadores: Donativos, viajes al extranjero o al interior del Imperio.

- Recepciones: Dadas a Ministros Plenipotenciarios

- Luto: El Emperador ordenaba guardar luto por la muerte de algún integrante de las casas reales europeas y daba los lineamientos a seguir para dicho acto.

Parte No Oficial: En ésta sección se publicaba las noticias concernientes al Imperio y a la situación política mundial, esto se hacía a través de la elaboración de artículos por los mismos editores de El Diario del Imperio o reproduciendo artículos de otros periódicos nacionales o extranjeros, para ello se dividía en:

Nacionales: Los temas aquí tratados eran:

- Enfrentamiento entre juaristas e imperialistas: Triunfos del ejército franco mexicano, ocupación de plazas, movimientos políticos o militares de Juárez o de sus aliados, aprehensión de disidentes y derrota de gavillas, estado de la paz pública.

- Peticiones de autoridades provinciales: Estas autoridades pedían al Emperador ayuda política, económica y militar para el buen funcionamiento de los gobiernos locales. 
- Acciones de autoridades: Se publicaban las actividades distinguidas de las autoridades locales o nacionales, civiles o militares, en el gobierno o en el campo de batalla.

- Correspondencia: Reproducción de la correspondencia oficial entre autoridades locales y nacionales (civiles o militares) respecto al estado que las cosas guardaban en cada punto conflictivo del imperio.

- $\quad$ Acciones de las Emperadores durante sus viajes.

Extranjeras: Los temas eran:

- Situación política mundial: Enfrentamientos diplomáticos o armados entre los países europeos o entre éstos y Estados Unidos. Relación entre Europa y América Latina.

- Guerra Civil Estadunidense: Desarrollo y desenlace, relación con el Imperio, conflictos diplomáticos con Europa.

- Acciones diplomáticas respecto al Imperio: Aquí se trataba las relaciones que el Imperio guardaba con los países europeos, Estados Unidos y la Santa Sede.

Dentro de las noticias extranjeras se insertaban los dos rubros siguientes:

Diplomáticas:

- Aceptación de los Ministros Plenipotenciarios del Imperio ante los países europeos, asiáticos, de Medio Oriente y América Latina.

- Correspondencia de felicitación por el advenimiento al trono de Maximiliano, emitidas por los gobernantes de los países con los que el Imperio tenía relaciones diplomáticas.

- Llegada de Ministros Plenipotenciarios o cónsules al Imperio. Ésta sección de noticias era intermitente, pues sólo aparecía publicada cuando había actos diplomáticos de relevancia.

Comerciales: 
- Importaciones y exportaciones a Europa (algodón, grana cochinilla, café, plata, cueros (chivo, res, venado), añil, cacao, etc.

- Estabilidad de los mercados y de los precios.

- Llegada de barcos nacionales o extranjeros a los puertos del Imperio y a los puertos extranjeros (Hamburgo, Nueva York, Havre, Veracruz, Acapulco, etc.) Ésta sección era intermitente.

DOCUMENTOS: En ésta sección se insertaban:

- Documentos oficiales provenientes de los distintos Ministerios, del Emperador, de los ayuntamientos, de la Escuela Imperial de Minas, de la Sociedad de Geografía y Estadística.

VARIEDADES: Se publicaban:

- Tratados sobre agricultura y cultivos de Añil, Trigo, Maíz, Arroz, Café, Grana Cochinilla, Frijol, Maguey, Lenteja, Algodón, con la finalidad de desarrollar las capacidades agropecuarias del país.

- Noticias geográficas y estadísticas de los Departamentos. Ésta sección era intermitente

- Algunas curiosidades sobre países extranjeros

Solicitudes: Tenían como objeto que el Emperador otorgara derechos sobre minas, colonización, deslinde de terrenos baldíos, diligencias, vapores, ferrocarriles y petróleo y públicamente se contestaba a dichas peticiones, manteniendo así la transparencia en el otorgamiento de gracias imperiales. Ésta sección era intermitente

ANUNCIOS OFICIALES: Avisos a las autoridades civiles o militares

- Sobre administración de rentas (remates)

- Correos

- Nacionalización de bienes 
- Recaudación de rentas

- Disposiciones sobre pensiones militares

- Eventos o inauguraciones

AVISOS JUDICIALES: Publicaban éstos avisos para el conocimiento de los interesados y hacer oficiales los fallos al respecto, sobre todo de los juzgados civiles

- Avisos sobre querellas entre particulares

- Publicación de sentencias

- Convocatorias para reclamo de herencias

- Convocatorias judiciales (comparecencia en juzgados)

\section{AVISOS PARTICULARES}

- Anuncios comerciales de compañías ferrocarrileras, de seguros, de transportes, imprentas, etc.

- $\quad$ Remates (Almonedas)

- Anuncios de medicamentos y boticas

- Avisos al público

- Avisos a los suscriptores de El Diario del Imperio

DIVERSIONES PÚBLICAS: Se publicaban funciones, horarios y costos, del teatro imperial, del teatro principal o del circo.

\section{CONSIDERACIONES FINALES}

Como podemos observar la prensa, durante el siglo XIX mexicano, formó parte activa de los conflictos derivados de la construcción política de la nación mexicana, situación que nos permite, al acercarnos a ella, obtener de primera mano la información para lograr un análisis de la ideología imperante en la época y utilizar como objeto de estudio a la prensa.

El Diario del Imperio, contribuyó a la estructuración de las actividades imperiales, además de convertirse en un importante vehículo de transmisión de información y de relación 
con los súbditos, en un territorio de grandes dimensiones, permitiendo el ágil funcionamiento de las ramas del gobierno, mediante la publicación de la legislación y las decisiones tomada por el emperador o sus ministros.

La importancia que el emperador depositó en su diario oficial, nos permiten conocer, desde otro ámbito el funcionamiento y las preocupaciones de las autoridades imperiales, a través de las referencias de la construcción y la utilización de la prensa, durante el Segundo Imperio Mexicano, echando luz sobre el papel de la prensa oficial durante este periodo histórico de México.

La lectura de El Diario del Imperio contribuye, sin duda alguna, a ampliar la comprensión de la historia de la prensa en México y particularmente a abordar desde otra perspectiva los estudios sobre el Imperio de Maximiliano, que a pesar de su efímera duración, dejó un importante legado para la formación de México como Estado-Nación.

El análisis de la estructura y la utilización del diario imperial de Maximiliano en México, que hasta aquí hemos realizado, pretende resaltar la importancia de los estudios históricos sobre la prensa, como fuente de información o como objeto directo de estudio, siempre tomando en cuenta que si bien, la prensa, por su propia naturaleza es subjetiva, eso no impide que la información que contiene y proporciona al historiador sea de inestimable valor, los mismo que cualquier otro documento histórico.

\section{Bibliografía}

Alonso, Paula (comp.). Construcciones impresas. Panfletos, diarios y revistas en la formación de los estados nacionales en América Latina, 1820-1920. México: Fondo de Cultura Económica, 2004.

Bosch García, Carlos. "Maximiliano en busca de reconocimiento" en Pompa y Pompa Antonio, compilador, De la Historia. Homenaje a Jorge Gurria Lacroix. México: IIHUNAM, 1865.

"Biografía de Guillermo Prieto", Instituto de Investigaciones Históricas, UNAM, acceso 6 de septiembre de 2017 , 
http://www.historicas.unam.mx/publicaciones/publicadigital/libros/lecturas/T2/LHM T2_028.pdf.

Castells, Manuel. Comunicación y poder. Madrid: Alianza editorial, 2009.

Castro, Miguel y Guadalupe Curiel (coords.). Publicaciones periódicas del siglo XIX: 18221855. México: Universidad Nacional Autónoma de México, 2000.

Coudart, Laurence. "La regulación de la libertad de prensa (1863-1867)", en Historia Mexicana. México: El Colegio de México, vol. 65, núm. 2 (258), octubre-diciembre 2015.

Covo, Jacqueline. La prensa en la historiografía mexicana: problemas y perspectivas, México: Historia Mexicana, UNAM, Vol. 52, 1993. http://codex.colmex.mx:8991/exlibris/aleph/a18_1/apache_media/QEGQULK77G6E JQM46B5VF1F3DLYHEJ.pdf.

Conte Corti, Egon Caesar. "Después de aceptar la corona” en Maximiliano y Carlota. México: Fondo de Cultura Económica, 2004.

De Habsburgo, Maximiliano, Estatuto Provisional del Imperio, México: 10 de abril de 1865, imprenta de Andrade y Escalante, Bajos de San Agustín, número 1, (5 de septiembre de 2017). http://www.ordenjuridico.gob.mx/Constitucion/1865.pdf.

González Cisneros, Luis Enrique y María Fernanda Rodríguez Tirado. "Ignacio Cumplido (Guadalajara, 1811- Ciudad de México, 1887) [Semblanza]”, en Alicante: Biblioteca Virtual Miguel de Cervantes, 2017.

Hernández, Angélica, "La libertad de Imprenta en la Ciudad de México durante el segundo Imperio" en Historias. Revista de Estudios Históricos del Instituto nacional de Antropología e Historia, México: INAH, no. 42, enero-abril 1999.

Matute, Álvaro, “Prensa, sociedad y política (1911-1916) en Aurora Cano Andaluz. Las publicaciones periódicas y la Historia de México. México: Universidad Nacional Autónoma de México, 1995. 
Navarrete Maya, Laura y Blanca Aguilar Plata (coord.). La prensa en México. Momentos y figuras relevantes (1810-1915). México, Pearson, 1998.

Pineda Soto, Adriana y Celia del Palacio Montiel (coord.). La prensa decimonónica en México: objeto y sujeto de la Historia. México: Universidad Michoacana de San Nicolás de Hidalgo/Universidad de Guadalajara/CONACYT, 2003.

Quirarte, Vicente, Ignacio cumplido, artista y empresario del siglo XIX, México: Instituto de Investigaciones Dr. José María Luis Mora, 2001.

Ross, Stanley Robert "El Historiador y el periodismo mexicano" en Historia Mexicana, México: El Colegio de México (27 de mayo de 2012). http://codex.colmex.mx:8991/exlibris/aleph/a18_1/apache_media/C15DIYLNEHX97 YIG5HE2RHXSP8LJTQ.pdf).

Ruedas de la Serna, Jorge, La Misión del escritor. Ensayos mexicanos del siglo XIX. México: Universidad Nacional Autónoma de México, 1996.

Ruiz Castañeda, María del Carmen (coord.). La prensa. Pasado y presente de México. México: Universidad Nacional Autónoma de México, 2da Edición, 1990.

Velasco Valdés, Miguel. Historia del periodismo mexicano (apuntes). México: Manuel Porrúa, 1955.

La república de las letras: asomos a la cultura escrita del México decimonónico. México: UNAM, Filológicas, Bibliográficas, Históricas, Vol. 2, 2005.

\section{Virtuales}

"Efemérides del periodismo mexicano", Cambio Digital, acceso 5 de septiembre de 2017,http://www.cambiodigital.com.mx/mosno.php?nota=71371\&seccion=Principal “ Efemerides del periodismo mexicano", Cambio Digital, acceso 6 de septiembre de 2017, http://www.cambiodigital.com.mx/mosno.php?nota=296454.

"Clemente de Jesús Munguía”, Memoria política de México, acceso 6 de septiembre de 2017, http://www.memoriapoliticademexico.org/Biografias/MCJ10.html.

\section{Hemerografía}


El Diario del Imperio, continuación del Periódico Oficial del Imperio Mexicano, (México, Imprenta de J. M. Andrade y F. Escalante (1865), Imprenta Imperial (1866-1867), $1^{\circ}$ enero 1865-19 junio 1867). 